
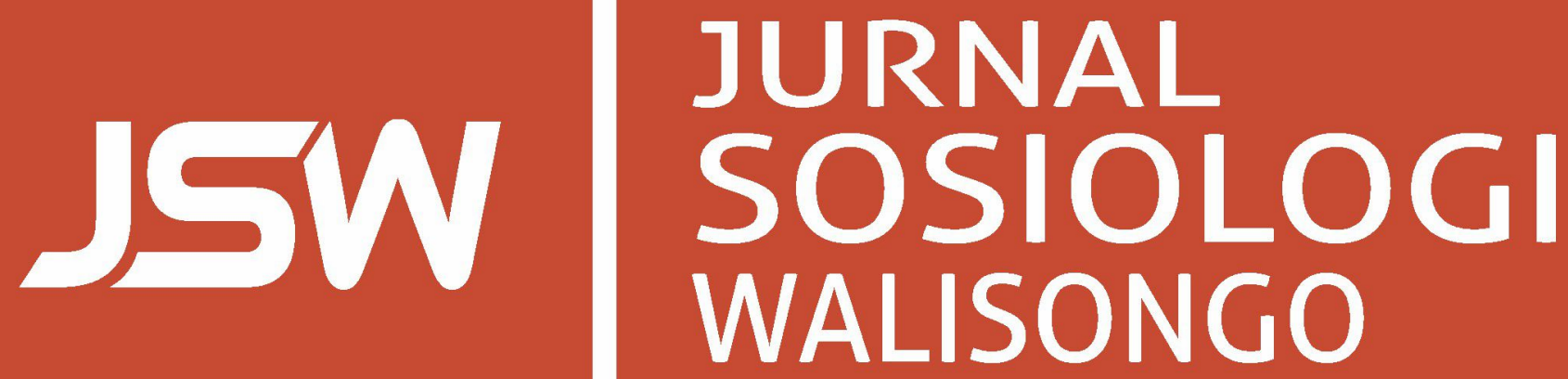

Studi Etnoekologi tentang Nelayan dan Jaring Cantrang

di Kabupaten Rembang

Hesti Rofika Sari, Nugroho Trisnu Brata

Perlawanan Visual Perempuan dalam Poster

Misbah Zulfa Elizabeth

Kearifan Budaya Lokal sebagai Benteng Munculnya Konflik Agama Muhammad Alfan Sidik

Ulama Pasca Sunan Gunung Jati: Jaringan Intelektual Islam Cirebon Abad ke-16 sampai dengan Abad ke-18

Didin Nurul Rosidin

Membangun Harmoni Sosial: Kajian Sosiologi Agama tentang Kearifan Lokal sebagai Modal Dasar Harmoni Sosial David Samiyono

Analisis Komparatif atas Hasil Tracer Study Program Studi Hubungan Internasional dan Administrasi Negara Muhyar Fanani, Akhriyadi Sofian, Kaisar Atmaja, Endang Supriadi

Melihat Indonesia dari Jendela Papua: Kebinekaan dalam Rajutan Budaya Melanesia Akhmad Kadir 

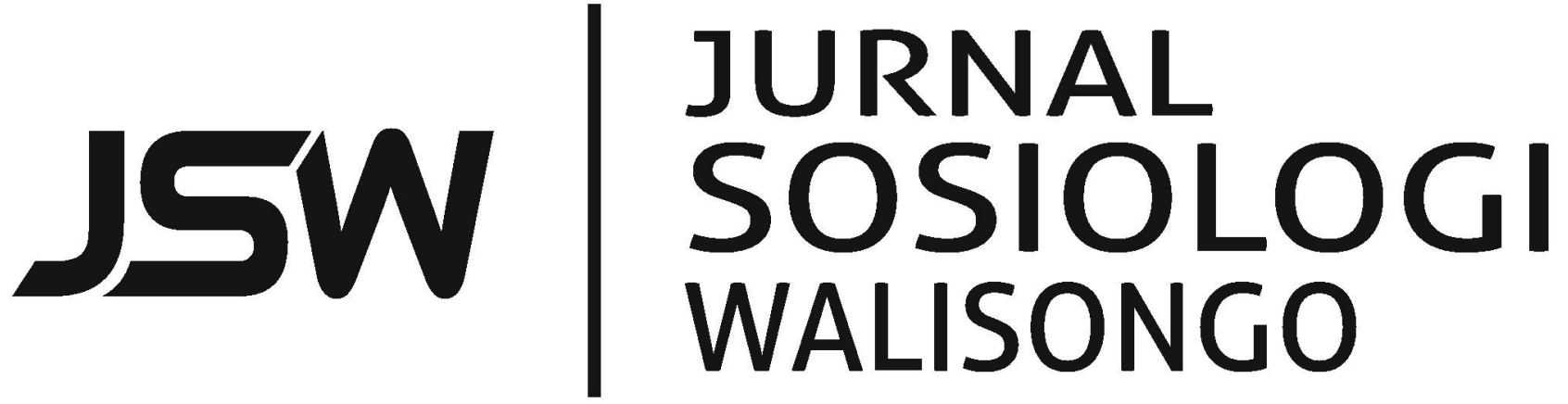

JSW: Jurnal Sosiologi Walisongo - ISSN 2503-3166 (print) ISSN 2503-3182 (online) is a critical, reflective, and transformative academic media that is published by Laboratorium Sosiologi, Fakultas IImu Sosial dan IImu Politik, Universitas Islam Negeri Walisongo Semarang, in the effort for developing the discipline of Sociology having the perspective of unity of sciences. Article is based on research in all division of sociology like sociology of religion, sociology of politic, sociology of law, sociology of development, urban/rural sociology, democracy, social ethic, anthropology, community development, social philosophy, gender, and social welfare.

\section{Editor in Chief}

Misbah Zulfa Elizabeth, Universitas Islam Negeri Walisongo, Semarang

\section{Expert Editor}

Abu Rokhmad, Universitas Islam Negeri Walisongo, Semarang

Muhyar Fanani, Universitas Islam Negeri Walisongo, Semarang

Thohir Yuli Kusmanto, Universitas Islam Negeri Walisongo, Semarang

\section{Editor}

Kaisar Atmaja, Universitas Islam Negeri Walisongo, Semarang

Akhriyadi Sofian, Universitas Islam Negeri Walisongo, Semarang

Nur Hasyim, Universitas Islam Negeri Walisongo, Semarang

\section{Layout Editor}

Helmi Suyanto, Universitas Islam Negeri Walisongo, Semarang

Ulul Azmi, Universitas Islam Negeri Walisongo, Semarang

\section{Publisher}

LABORATORIUM SOSIOLOGI

Fakultas IImu Sosial dan IImu Politik

Universitas Islam Negeri Walisongo

Semarang - Indonesia

\section{Address}

Gedung A - Fakultas IImu Sosial dan IImu Politik (FISIP)

Universitas Islam Negeri Walisongo, Semarang - Indonesia

Jl. Prof. Dr. HAMKA, Km. 2 Tambakaji Ngaliyan Semarang 50185

Phone +62.24 - 76435986

e-mail:jurnal.sosiologi@walisongo.ac.id 


\section{Table of Contents}

Studi Etnoekologi tentang Nelayan dan Jaring Cantrang di Kabupaten Rembang

Hesti Rofika Sari, Nugroho Trisnu Brata (Universitas Negeri

Semarang)

$135-146$

Perlawanan Visual Perempuan dalam Poster

Misbah Zulfa Elizabeth (Universitas Islam Negeri Walisongo,

Semarang)

$147-160$

Kearifan Budaya Lokal sebagai Benteng Munculnya

Konflik Agama

Muhammad Alfan Sidik (STAI Natuna)

$161-176$

Ulama Pasca Sunan Gunung Jati: Jaringan Intelektual Islam

Cirebon Abad ke-16 sampai dengan Abad ke-18

Didin Nurul Rosidin (Institut Agama Islam Negeri Syekh Nurjati,

Cirebon)

$177-194$

Membangun Harmoni Sosial: Kajian Sosiologi Agama tentang

Kearifan Lokal sebagai Modal Dasar Harmoni Sosial

David Samiyono (UKSW, Salatiga)

$195-206$

Analisis Komparatif atas Hasil Tracer Study Program Studi

Hubungan Internasional dan Administrasi Negara

Muhyar Fanani, Akhriyadi Sofian, Kaisar Atmaja, Endang Supriadi

(Universitas Islam Negeri Walisongo, Semarang)

$207-224$

Melihat Indonesia dari Jendela Papua: Kebinekaan dalam

Rajutan Budaya Melanesia

Akhmad Kadir (Universitas Cendrawasih, Jayapura)

$225-246$

Author Guidelines

JSW: Jurnal Sosiologi Walisongo - Vol 1, No 2 (2017) 



\title{
Kearifan Budaya Lokal sebagai Benteng Munculnya Konflik Agama
}

\author{
Muhammad Alfan Sidik \\ Sekolah Tinggi Agama Islam (STAI) Natuna \\ (e-mail: alfanfred@yahoo.co.id)
}

\begin{abstract}
Practically religion and culture can't be separated, although in the theoretical sphere they can be separated. Religion can be practiced by its adherents through culture. Basically Religion comes to humans who had been had a culture. Long before the coming of religion, in fact people with their intellect and conscience are able to have a noble culture, which saves each other and is able to create a harmonious life. However, it is precisely in this modern era when humans who claim to reach the peak of advanced culture, it is often a conflict in the name of religion. The birth of religion should be to complete the noble culture, in the contrary, religion and local culture indeed experience tension which trigger conflict sometimes. Humans who only had cultured, can life together in harmony although pre-religions. Unfortunately when there comes aren't time in which religion and culture have been developed of there life aren't harmonious. This paper will discuss the relationship between religion and culture in relation to conflict. Analysis of the crisis of modernity which also result in narrowmindedness cause the emergence of conflic.
\end{abstract}

\begin{abstract}
Secara praktis, agama dan budaya tidak dapat dipisahkan, meskipun dalam lingkup teoretis mereka dapat dipisahkan. Agama dapat dipraktekkan oleh penganutnya melalui budaya. Pada dasarnya agama datang kepada manusia yang telah memiliki budaya. Jauh sebelum datangnya agama, sebenarnya orang dengan kecerdasan dan hati nurani mereka mampu memiliki budaya yang luhur, yang saling menyelamatkan dan mampu menciptakan kehidupan yang harmonis. Namun, justru di era modern ini ketika manusia yang mengaku mencapai puncak budaya maju, seringkali terjadi konflik atas nama agama. Agama lahir seharusnya untuk menyempurnakan kebudayaan yang sudah luhur, namun yang terjadi sebaliknya agama dan budaya lokal justru mengalami ketegangan yang kadang memicu konflik. Manusia yang hanya berbudaya pada zaman dahulu, meskipun pra-agama mampu hidup dengan harmonis. Namun justru ketika datang suatu zaman di mana agama dan budaya sudah sedemikian berkembangnya seringkali hidup tidak berjalan harmonis. Tulisan ini akan membahas hubungan antara agama dan budaya dalam kaitannya dengan konflik. Analisis tentang adanya krisis kemodernan yang juga ikut berperan dalam memunculkan kejumudan berfikir yang mengakibatkan munculnya konflik.
\end{abstract}

Keywords: religion; culture; conflict; modernity 


\section{Pendahuluan}

Konflik agama semakin mengkhawatirkan, dan penyebabnya menurut penulis adalah hal-hal yang semakin sepele dan tidak rasional. Hanya karena seseorang melakukan ziarah di suatu makam kemudian makam itu diserbu oleh sekelompok ormas Islam yang menganggap bahwa itu praktik syirik atau menyekutukan Tuhan.

Konflik agama sebenarnya dapat dideskripsikan lebih panjang sebagai konflik antar manusia yang diakibatkan perbedaan pemahaman (baca: penafsiran) terhadap suatu doktrin agama. Konflik itu muncul ketika pemahaman atas agama diyakini sebagai bukan lagi pemahaman/ penafsiran atas agama, menurut hemat penulis, bahkan pemahaman tersebut dianggap sebagai doktrin agama itu sendiri, sehingga pemahaman mereka dianggap sebagai satu-satunya kebenaran, yang oleh M. Arkoun disebut Taqdis al-afkar al-dini (penyakralan pemikiran keagamaan). Sikap semacam ini menjadi salah satu sumber eksklusivisme agama yang mengakibatkan kejumudan umat dan cenderung mudah melakukan takfir (pengkafiran) terhadap kelompok yang dianggap berbeda pemahaman tentang agama. Maka sikap yang sering muncul adalah intoleransi dan berakhir pada radikalisme terhadap kelompok yang dianggap menyimpang atau sesat.
Agama diturunkan kepada manusia mempunyai suatu misi, di mana misi itu adalah agar manusia mampu mencapai kesempurnaan, baik secara individu maupun sosial. Maka seharusnya nilai-nilai sakral agama semacam ini ketika diimplementasi-kan oleh pemeluknya bisa memberikan perdamaian, bukan konflik destruktif yang berkepanjangan pada masyarakat. Sehingga aktualisasi nilai-nilai sakral agama tersebut memungkinkan dapat mencegah munculnya konflik agama.

Di zaman pra-Islam, setiap wilayah khususnya di Nusantara, sudah mempunyai sistem kepercayaan dan budaya tertentu, yang memiliki keluhuran, kearifan, dan bermuatan spiritual. Di Melayu misalnya, suku tertua Melayu, Melayu tua (proto Melayu) sudah mendiami tanah Melayu sekitar tahun 3000-2500 Sebelum Masehi. Kemudian Melayu muda (Deutro Melayu) tiba sekitar tahun 300-250 Sebelum Masehi, dengan perjalanan sejarah yang cukup panjang itu, sangat memungkinkan bahwa suatu bangsa atau suku memiliki budaya yang lebih luhur, bahkan dari budaya modern sekarang ini. Sebagai bukti misalnya, bangsa dahulu dalam memandang alam semesta adalah sebagai bagian dari kehidupan mereka, sehingga sikapnya terhadap alam adalah keseimbangan, pelestarian, bukan ekploitasi berlebihan yang mengakibatkan kerusakan alam. Mereka hidup bersama dalam keharmonisan, bukan hanya sesama manusia namun juga dengan alam, 
mereka memperlakukan alam sebagai partner yang memiliki jiwa yang halus. Makhluk yang menghuni tanah dinamakan Jembalang, yang mengawal binatang dan burung dinamakan Sikodi, yang menghuni hutan dinamakan Mambang. Bahkan jiwajiwa yang menampakkan wujudnya sebagai wanita cantik dinamakan Peri. (Hamidy 2014: 4-5, 87)

Begitu juga di daerah lain Nusantara di Jawa misalnya mempunyai filosofi hidup Mamayu hayuning bawono yang artinya mengusahakan keselamatan hidup di seluruh alam, yang semangatnya hampir sama dengan rahmatan li l-álamin (rahmat bagi seluruh alam), juga mirip dengan spirit filosofi negara Bhinneka Tunggal Ika (berbeda-beda namun tetap satu jua).

Bangsa Indonesia melalui pengalaman hidupnya dan perjalanan kesejarahannya mampu mempunyai filosofi yang luhur semacam itu, mungkin membutuhkan penelitian secara historis dan antropologis. Setidaknya mampu dilihat bahwa manusia dengan sisi kebudayaannya yakni dengan tradisi yang berakar dari akal budi dan hati nuraninya dalam merenungi kehidupan-bahkan untuk tidak mengatakan tanpa agama, sebenarnya telah mampu mencapai kearifan-kearifan lokal yang tinggi, yang mampu menciptakan kehidupan damai sejahtera dan saling menyelamatkan satu sama lain.

Tulisan ini akan membahas munculnya api konflik atas nama agama, dari sudut pandang bahwa manusia sebelum menjadi pemeluk suatu agama, sudah memiliki budaya yang luhur, yang menjunjung tinggi perdamaian, lantas kenapa ketika memasuki abad modern ini ketika manusia sudah mempunyai agama, cenderung mudah marah dan melakukan konflik. Maka tulisan ini akan membicarakan manusia dan budayanya sebagai bekal untuk memberikan kedamaian bagi kehidupan.

\section{Pemahaman Agama dan Budaya}

Secara historis, agama dipandang sebagai bagian yang tak terpisahkan dari proses dinamika sejarah dan budaya. Agama dan budaya meskipun dalam wacana teoritis dapat dipisahkan, namun tak pernah terpisah dalam ranah praktis. Agama secara normatif itu sakral, namun ketika agama dijalankan oleh pemeluknya atau secara historis, akan memunculkan pengalaman keagamaan, maka secara historis agama menjadi profan dan mau tidak mau agama akan menjadi bagian dari budaya.

Masyarakat yang mendiami suatu daerah mempunyai kebiasaan (habit) tertentu. Kebiasaan tertentu itu apabila dilakukan secara terus menerus kemudian menjadi sebuah tradisi atau adat. Dalam perjalanan selanjutnya, tradisi itu kemudian menjadi budaya, yaitu ketika tradisi-tradisi itu sudah tersaring dengan nilai-nilai kerohanian yang dianut oleh 
masyarakat. Jadi budaya adalah suatu tradisi yang sudah bernilai rohaniah; artinya sudah bernilai bukan hanya indah namun juga bernilai luhur. Hal ini sejalan dengan akar kata budaya itu sendiri, yang berasal dari bahasa Sansekerta buddhi artinya hal-hal yang berkaitan dengan budi dan akal manusia (Efendy 2012: 31). Maka kebudayaan dapat juga diartikan sebagai hasil dari kegiatan (cipta, karya, karsa) manusia. Itu dapat berupa kepercayaan, kesusastraan, kesenian dan tradisi-tradisi lainnya.

Agama hadir di dunia yang setiap jengkal wilayahnya mempunyai budaya yang tak mungkin sama, karena dipengaruhi oleh perbedaan kondisi alam, iklim dan cuacanya. Bahkan di satu jengkal wilayah, bisa mempunyai keragaman budaya. Misalnya di Arab sebagai tempat awal perkembangan Islam, memiliki keragaman budaya, antara Mekah dan Madinah pada masa itu keduanya mempunyai budaya yang berbeda meskipun tidak terlalu jauh perbedaannya. Masyarakat Mekah memiliki naluri dagang yang kuat karena tanah mereka tandus tidak bisa ditanami. Sementara penduduk Madinah lebih suka menanam karena tanah mereka relatif subur. Oleh karena itu sektor pertanian memperoleh perhatian utama Nabi Muhammad saw dalam membangun ekonomi Madinah. Beliau tahu benar bahwa karakteristik penduduk Madinah berbeda dengan Mekah.
Agama dan budaya juga sering disalahpahami wilayah perbedaannya, misalnya dalam melihat sejarah Nabi saw, yang awalnya adalah seorang pedagang, kemudian dapat disimpulkan bahwa Islam itu adalah agama dagang. Bahwa Nabi saw ketika muda adalah seorang pedagang yang sukses, namun bukan berarti dapat disimpulkan bahwa Islam adalah agama dagang, yang kemudian menganjurkan pemeluk Islam untuk berdagang. Jika dilihat dari aspek budaya, Nabi saw hidup di Mekah yang mayoritas penduduknya saat itu adalah pedagang maka Nabi bekerja sebagai berdagang, tatkala Nabi saw berada di Madinah Nabi tidak menyuruh penduduk Madinah untuk berdagang namun bertani, karena secara sosiologi penduduk Madinah saat itu merupakan masyarakat yang plural dan mayoritas adalah bertani.

Contoh lain perihal budaya adalah suatu ketika Nabi ditanya oleh petani perihal tanaman kurma, namun Nabi menjawabnya 'antum a'lamu bi umūri aldunyākum' (kalian lebih tahu tentang urusan duniamu). Istilah 'umuri al-dunyākum' (urusan duniamu) mempunyai cakupan makna yang luas, maka tidak berlebihan jika "umūri al-dunyākum" dapat juga dimaksudkan sebagai kebudayaan. Artinya dalam hal kebudayaannya, masyarakat lebih mengetahui tentang budaya sendiri, oleh karena itu, masyarakat memiliki kebebasan dalam berbudaya, asalkan itu 
sesuai dengan ajaran Agama. Dengan istilah lain, dalam praktek agama dalam sisi historisitasnya seharusnya tidak lagi memiliki ketegangan (tension) dengan sisi normativitasnya. Sisi historisitas yang dimaksud adalah sebagaimana sabda Nabi saw. adalah antum a'lamu bi umūri aldunyākum' (kalian lebih tahu tentang urusan duniamu).

Agama dan budaya lokal adalah bagian yang tak terpisahkan dalam praktiknya, agama mengajarkan shalat dengan berbagai syarat dan ketentuannya, namun dalam prakteknya shalat itu juga membutuhkan budaya, dalam artian bahwa orang shalat menggunakan pakaian yang sopan, peci, sajadah, masjid, microphone dan lain sebagainya, yang semua itu tidak lain adalah produk dari budaya. Setiap daerah memiliki keragaman dengan daerah lainnya. Secara praktis, kebutuhan agama kepada budaya adalah bagian dari sendi-sendi kehidupan atau sebuah keniscayaan hidup (min lawazim al-hayah) kata pepatah Arab, sehingga tinggal bagaimana kita me-manage keduanya sehingga tidak terjadi ketegangan (tension) bahkan konflik.

\section{Budaya sebagai Benteng Timbulnya Konflik}

Setiap budaya di suatu tempat memiliki karakteristik yang unik, karena setiap tempat memiliki, karakteristik alam, iklim, manusia, dan pengalaman kesejarahannya yang berbeda-beda. Dalam hal ini alQur'an mengajarkan untuk saling mengenal;

Hai (seluruh) manusia! Sesungguhnya Kami menciptakan kamu dari seorang lakilaki dan seorang perempuan serta menjadikan kamu berbangsa-bangsa dan bersuku-suku, supaya kamu saling kenalmengenal. Sesungguhnya yang paling mulia di antara kamu di sisi Allah ialah yang paling bertakwa di antara kamu. Sesungguhnya Allah Maha Mengetahui, lagi Mahateliti. (QS. Al-Hujurat: 3).

Al-Qur'an mengajarkan untuk saling mengenal satu sama lain, untuk saling belajar antar budaya dan suku yang berbeda. Setiap budaya memiliki keunikan tersendiri dengan budaya lain, keunikan ini bukan bukanlah untuk saling bermusuhan namun untuk saling mengenal, sebagai jalan untuk saling melengkapi kekurangan budayanya masing-masing. Satu misal, kalau dalam budaya Barat lebih mementingkan rasionalitas, sedangkan budaya Timur lebih mementingkan rasa cinta kasih, oleh karena itu, dengan saling mengenal akan memungkinkan keduanya memiliki keseimbangan antara rasionalitas dan rasa cinta kasih.

Dalam khazanah Jawa terutama di masyarakat lereng Merapi misalnya ada ungkapan "Jowo digowo, Arab digarap, Barat diruwat", ${ }^{1}$ Maksudnya adalah meski-

${ }^{1}$ Artinya "Jawa dibawa, Arab dibumikan, Barat dibersihkan". 
pun Islam namun tidak kehilangan karakteristik kearifan lokalnya, ke-jawa-annya. Arab digarap, artinya Arab harus dibumikan di tanah Nusantara diakulturasikan dengan budaya lokal, Barat harus diruwat artinya kebudayaan Barat tidak ditolak, namun harus disaring, dilakukan sterilisasi sedemikian rupa agar 'racun-racun' dalam arti unsur-unsur negatif dari budaya Barat, yang berbahaya tidak ikut masuk ke dalam budaya Nusantara.

Seringkali budaya dianggap paling sedikit tidak penting dan paling buruk dianggap dapat mendistorsi agama, karena dianggap sebagai bid'ah bahkan dianggap praktek kesyirikan, sebagaimana dijelaskan sebelumnya budaya adalah bagian yang tak terpisahkan dengan Agama, misalnya dalam khazanah tasawuf, Haidar Bagir dalam sebuah seminar pernah mengatakan bahwa budaya tidak kalah sakral dengan agama, karena budaya itu bagian dari agama. Dalam tradisi tasawuf betapa sentralnya budaya dalam agama, karena yang paling banyak membawa budaya ke dalam agama adalah kaum Sufi, bisa berupa sya'ir, tari-tarian, ataupun kesenian lainnya.

Menurut Haidar Bagir, sya'ir dianggap jauh lebih mampu menampung dan membawa makna spiritual atau pengalaman spiritual seorang sufi dibanding melalui prosa biasa, para penyair sufi misalnya Jalaludin Rumi, Ibn 'Arabi, M. Iqbal. Sastr- awan besar lainnya yang lahir di Melayu misalnya: Raja Ali Haji, Hamzah Fansuri, Nurudin ar-Raniry, Ali Kelana dan Raja Haji Ahmad.

Islam yang masuk di Nusantara, ${ }^{2}$ adalah Islam yang bercorak tasawuf. Menurut A.H. Johns seorang sarjana Barat, Islam tidak akan pernah bisa berakar di Kepulauan Melayu ${ }^{3}$ hingga berkembangnya tarekat-tarekat sufi, dan bahwa cepatnya penyebaran Islam setelah abad ke-7 H/13 M terutama berkat kerja keras para juru dakwah sufi. Bukti jelas lainya adalah dalam karya al-Attas tentang segenap gagasan dan ajaran Hamzah al-Fanshuri, seorang penyair sufi Melayu abad ke-10 H/16 M. Dalam karyanya, al-Attas mengungkapkan bahwa tasawuf tumbuh dan berkembang secara sedemikian rupa sehingga pastilah memiliki pengaruh penting dalam pengislaman kepulauan Melayu yang berskala besar (Bakar, dalam Nasr 2003: 343).

Islam yang diterima di Nusantara adalah Islam yang bercorak tasawuf, yang dibawa oleh para wali sufi yaitu para walisanga, ketika bersentuhan dengan kebudayaan lokal pra-Islam melahirkan karakteristik-karakteristik unik yang mem-

\footnotetext{
${ }^{2}$ Nusantara dalam arti wilayah Indonesia, dalam skala waktu sejak abad ke- 7 hingga abad ke- $19 \mathrm{M}$.

${ }^{3}$ Wilayah Kepulauan Melayu yang dimaksud A.H. Johns dalam pembahasan di tulisan tersebut adalah wilayah kepulauan nusantara (Indonesia).
} 
buat segenap upaya dakwah para wali sufi lebih berhasil. Para wali sufi itu menggunakan kearifan lokal sebagai medium dakwah, karena masyarakat sudah lazim dan terkait erat dengan konsep-konsep dan Weltanschauung lama mereka. Para wali sufi ini, yaitu "walisongo", mendakwahkan Islam dengan menggunakan media budaya lokal, misalnya media wayang yang dilakukan oleh Sunan Kalijaga untuk menyebarkan Islam di Jawa.

Karakteristik lainnya yang diketahui telah menarik banyak mualaf adalah kekuatan spiritual tertentu yang dimiliki oleh kaum sufi. Sebagaimana ditampakkan, misalnya, dalam menyembuhkan penyakit. Bangsa Nusantara menyebut kekuatan supernatural ini keramat, yang merupakan perubahan kata dari bentuk aslinya dalam bahasa Arab karamat.

Bukan hanya kekuatan spiritual pada kaum sufi, namun juga pada benda-benda peninggalannya yang dianggap sakral disebut bertuah. Tempat tetentu yang memberi peluang untuk dihuni oleh makhluk halus, seperti rimba, tanjung, lubuk dan beting disebut sakti, karena dapat memberi tindak balas yang berbahaya jika diperlakukan sesuka hati. Peninggalanya seperti kuburan orang saleh juga disebut keramat tidak boleh dipakai tempat mendirikan bangunan (Hamidy 2014: 878). Dengan mengakui kecenderungan mistis yang kuat dari bangsa Melayu dan kecondongan mereka pada apa yang akan dan telah diberikan oleh kaum sufi ini, A.H.
Johns berkomentar bahwa "Islam jenis Wahhabi" hanya akan berpengaruh kecil di wilayah seperti Jawa. (Bakar, dalam Nasr 2003: 352-353). Artinya Islam jenis tasawuf lebih sesuai dengan budaya lokal Nusantara.

Oleh karena itu ketika Islamisasi di wilayah Nusantara terutama di tanah Jawa dan Melayu, adalah Islam yang dibawa oleh para wali sufi, kemudian berakulturasi dengan kearifan budaya lokal, output-nya adalah kebudayaan Islam yang secara historis sudah matang, yang berbeda dengan budaya Islam di daerah dan tempat lain. Kebudayaan Islam Nusantara umumnya memiliki karakteristik yang unik cinta damai dan tidak militant.

Sebagaimana Azzumardi Azra, bahwa Islam di Asia Tenggara menurutnya mempunyai sebuah kekhasan, yang berbeda dengan watak Islam di kawasan lain, khususnya di Timur Tengah. Azra mencontohkan, di antara karakteristik terpenting Islam di Asia Tenggara itu, misalnya, watak yang lebih damai, ramah, dan toleran (Azra 2000: xv). Kemudian Azzumardi Azra, memperkuat pendapat itu dengan pengakuan banyak pengamat tentang keunikan karakteristik tersebut. Di antaranya Thomas W. Arnold, dalam buku The Preaching of Islam (1950) yang memberi penjelasan tentang keunikan tersebut dimulai sejak proses Islamisasi di Asia Tenggara yang berlangsusng secara damai; dalam istilah Arnold disebut penetration pacifigure, yang memang berbeda 
dengan penyebaran Islam di wilayah lain, yang sering melibatkan kekuatan militer (Azra 2000: xvi).

Akhirnya Azzumardi Azra, memberikan satu catatan penting bahwa Penyebaran Islam di Asia Tenggara yang damai seperti itu, bahwa Islam di Asia Tenggara lebih "lunak", lebih "jinak", atau sangat "akomodatif" vis a vis kepercayaan, praktek keagamaan, dan tradisi lokal.

Tarekat-tarekat sufi Melayu telah mempengaruhi pandangan orang Melayu mengenahi sistem politik dan tatanan sosial mereka, terkecuali oleh satu atau dua kejadian, orang Melayu tidak pernah dikenal menampakkan radikalisme agama (Bakar, dalam Nasr 2003: 368).

Jadi kebudayaan Islam Nusantara memiliki kekhasan tersendiri yaitu cinta damai dan tidak militant, yang cenderung bercorak mistis, karena bernuansa tasawuf. Islam Nusantara seharusnya Islam yang sangat Rahmatan li al-'alamin, yang berkasih sayang dan saling menyelamatkan satu sama lainnya. Tidak mudah marah dan dewasa dalam menerima perbedaan. Oleh karena itu, Emha Ainun Nadjib (2014) pernah mengatakan, bahwa ada 3 macam bentuk pertahanan untuk rakyat Indonseia. Pertama adalah pertahanan tradisi dan kebudayaan. Kedua, pertahanan intelektual. Ketiga, pertahanan politik dan militer. Kearifan budaya lokal Nusantara, adalah bagian dari bentuk pertahanan dari konflik agama.

\section{Krisis Modernisme dan Posmodernisme}

Di antara faktor lain yang ikut berperan dalam munculnya konflik agama adalah adanya krisis yang terjadi di era modern dan postmodern. Krisis yang membuat manusia melupakan kebudayaannya sendiri, yang justru jauh lebih luhur. Manusia yang mengalami krisis kemodernan, ketika mempelajari ilmu agama atau suatu doktrin agama, memiliki kecenderungan kehilangan rasa kemanusiaan dan cenderung menjadi anarkis.

Dalam bukunya Megatrend 2000, John Naisbitt meramalkan apa yang akan terjadi dalam milenium kedua ini bahwa dalam waktu yang kacau, banyak perubahan, manusia bergerak menuju dua arah ekstrem; fundamentalis atau pengalaman spiritual personal (Naisbitt dan Aburdene 1990: 6-7). Dua ekstrem ini sekarang cenderung lebih diminati oleh banyak orang bahkan di beberapa tempat kemudian menjadi gerakan yang mainstream.

Terjadinya krisis sosial dan krisis kemanusiaan, dapat membikin manusia yang hidup di era posmodern mengalami chaos kehidupan, yang diakibatkan oleh kompleksitas dari warisan krisis modernitas, yang dimulai sejak era renaisans di Barat. Di era itu muncul semangat-semangat kemanusiaan, ini bisa dilihat dari munculnya paham antropo- 
sentrisme sebagai sikap kritisnya terhadap teosentrisme Abad Pertengahan. Muncul juga ideologi humansime yang dapat dipandang sebagai upaya intelektual yang gigih untuk memaknai kemanusiaan dan keterlibatan manusia di dalam dunianya (Hardiman 2012: 27).

Kesadaran kemanusiaan yang berasal dari paham antroposentrisme kemudian melahirkan kaum agnotis, the deits, ataupun ateis pada masa itu, mereka banyak menulis buku-buku kontroversial mencoba meyakinkan bahwa kekuasaan Tuhan tidak lagi dapat dilacak pada mukjizat-mukjizat-Nya, melainkan pada alroji semesta yang mencerminkan suatu desain Tuhan. Oleh karena itu mereka beranggapan bahwa moralitas tidak harus diturunkan dari wahyu Tuhan, melainkan cukup disimpulkan dari asas akal budi kita sendiri dan mekanisme alam, yang terinspirasi dari Isaac Newton (16431727) dengan fisikanya ia memberi kita suatu keyakinan rasional bahwa alam bekerja secara mekanistis seperti alroji, dan akal budi manusia dapat menyingkap hukum-hukum yang bekerja di belakang proses-proses alamiah (Hardiman 2012: $10)$.

Meskipun kesadaran kemanusiaan yang antroposentris pada akhirnya memberikan kemajuan teknologi, namun manusia cenderung melupakan kebudayaannya sendiri. Manusia tidak lagi menjunjung tinggi keharmonisan dengan alam, ia tidak lagi menganggap alam adalah partner tapi alam adalah lahan eksploitasi. Akibatnya muncul masalah baru, seperti krisis sosial dan krisis ekologi yang tak lain disebabkan eksploitasi alam secara berlebihan, terutama pasca Revolusi Industri (1750-1850), di mana banyak kerusakan yang diakibatkannya. Tak kalah berbahaya dari krisis tersebut adalah krisis eksistensial, karena di era teknologi, manusia harus bersaing dengan mesin, bahkan manusia harus berjalan sebagaimana mesin yang digerakkan oleh para kapitalis. Sebagaimana pandangan dunia mekanistis ala Newton, yang hanya berfokus pada objek-objek material ansich tanpa penghayatan. Maka manusia yang mengalami krisis eksistensial. Manusia menjadi teralienasi dari dirinya sendiri sebagai subjek pemberi makna, hidupnya menjadi hampa tanpa makna.

Manusia yang mengalami krisis eksistensial, tak kunjung juga mendapatkan kedamaian dalam hatinya, akhirnya ia kecewa dengan abad modern, sebagaimana kata Nasr dalam The Plight of Modern Man yang dikutip Haidar Bagir, bahwa krisis-krisis eksistensial semacam ini bermula dari pemberontakan manusia modern kepada Tuhan, mereka telah kehilangan harapan akan kebahagiaan masa depan seperti yang dijanjikan oleh Renaisans, Abad pencerahan, Sekularisme, Sains, dan Teknologi (Bagir, dalam Oliver Leaman, 2001: xiii). Krisis eksistensial ini 
juga lahir dari matinya kebudayaan, manusia lupa dengan kearifan budayanya sendiri

Puncak dari krisis-krisis di atas adalah pada awal abad 21 ini, penanda lain yang mendesak untuk dipikirkan ulang, tentang hubungan kemodernan dan agama (nalar dan iman) adalah peristiwa 11 September 2001 atau dikenal dengan 9/11. Manusia mengalami relativisme, yang dibawa oleh rasio sekuler, dimana relativisme berpandangan bahwa sebuah kebenaran dianggap tak terjangkau, relativisme agama berpendapat semua agama adalah sama benarnya, hal ini membuat penilaian moral bersama sulit diraih, (seperti kesulitan menjawab apakah membunuh dan menganiaya manusia itu benar atau salah). Hal tersebut yang justru telah menyediakan ruang bagi fundamentalisme yang mengklaim kebenaran absolut cenderung agresif dan tidak toleran, karena itu sulit hidup berdampingan dengan orang lain di zaman modern, karena di tengah-tengah krisis dan disorientasi nilai, sikap-sikap fundamentalistik memiliki daya tarik tersendiri dalam jiwa yang mencari kepastian dan koherensi. (Hardiman 2012: 73).

Kecenderungan-kecenderungan yang negatif ini, sebenarnya adalah bagian dari paradoks masyarakat posmodern, karena dunia menjadi global. Menurut Amin Abdullah di era global, manusia mengalami semacam kegamangan dalam meniti kehidupan, yang diakibatkan terjadi kesimpangsiuran lalu lintas informasi tentang Islam di era yang ia sebut borderless society. Klaim-klaim keislaman secara sepihak-subjektif, semakin hari semakin membingungkan masyarakat dan semakin tak terkontrol oleh siapapun dan oleh lembaga apapun, yang semakin kebal akan kritik (Abdullah, dalam Marwan Saridjo, ed. 2009: 264-65). Kegamangan semacam inilah yang kemudian akan memunculkan pola keislaman yang fundamentalis exsklusif dan pada akhirnya memicu radikalisme bahkan terorisme.

Manusia di era posmodern ini adalah manusia yang hidup di zaman di mana ia berada dalam horison sangat besar. Banyaknya terpaan informasi, membuat keyakinan menjadi goyah dan menjadi tidak berdaya. Manusia tidak bisa merasa aman dengan sesuatu yang diyakininya. Hal inilah yang membuat manusia mengalami semacam tekanan psikologis. Seseorang semakin cenderung untuk berkumpul dengan masyarakat primordial, karena seseorang membutuhkan pegangan atau kepastian. Posmodernistik ini menghasilkan goncangan yang membuat manusia tidak bisa berpegang pada satu hal yang pasti, maka orang semakin ingin berkumpul dengan yang mempunyai kesamaan dengan dirinya, berbagai komunitas dan ormas-ormas pun bermunculan sebagai reaksi gempuran posmodernisme. 
Salah satu ekses negatif dari munculnya paradoks posmodern adalah munculnya kelompok-kelompok fundamentalisme dan radikalisme. Di Indonesia misalnya, karena bermunculan ormas-ormas Islam, di sisi lain mereka sudah terkena krisis kemodernan, melupakan jauh identitas budayaannya sendiri, semakin menambah kebingungan. Dahulu ormas-ormas yang dikenal di Indonesia hanyalah ormasormas besar, seperti Nahdlatul Ulama' (NU), Muhammadiyah, Nahdlatul Wathan (NW), dan ormas besar lainnya, yang sudah menjadi bagian dari sejarah dan dinamika kebudayaan Indonesia, sedangkan sekarang, kelompok-kelompok Islam baru bermunculan dari luar, yang bermacam-macam jenisnya, yang masingmasing mengklaim memiliki dasar pembenaran sendiri.

Berbagai bangsa memiliki karakteristik Islam yang berbeda-berda, sesuai dengan karakteristik kebudayaannya, Islamnya orang Saudi, Islamnya orang Amerika, Europian Islam, dan lain sebagainya, kemudian ada aliran-aliran seperti Salafi, baik yang takfiri maupun bukan, dan banyak sekali bermacam-macam pandangan yang berbeda. Sebenarnya bagi penganut muslim tradisionil gejolak Islam yang berbeda-beda seperti ini tidaklah terlalu mendapat pengaruh yang besar, namun bagi mereka yang terkena paradoks posmodernisme yang mengalami krisis eksistensial, yang mendapatkan pengaruh cukup besar.
Meminjam pemikiran lama dari Ernest Gellner (1992: 9-14) yang membagi dua cara penghayatan Islam, pertama; hight Islam (Islam tinggi) yaitu cara penghayatan Islam di mana kehidupan dan Islam itu masih ada kesenjangan, dan kedua; Low Islam (Islam rendah) Islam yang sudah menjadi bagian organik dari kehidupan masyarakat. Islam yang dipahami sebagian besar orang Indonesia pada umumnya adalah low Islam. Sedangkan higth Islam, dipahami sebagai orang fundamentalisme, karena dia selalu melihat gap antara ideal Islam dan bagaimana kehidupan bermasyarakat. Gap inilah yang sering memunculkan kekecewaan terhadap realitas kehidupan masyarakat karena tidak sesuai dengan idelitas Islam.

\section{Budaya Sebagai Produk Akal Budi dan Hati Nurani}

Budaya adalah hasil cipta, karya, dan karsa manusia, yang berasal dari akal budi dan hati nurani manusia, yang dalam sejarah manusia, menjadi modal manusia untuk memperoleh kebijaksanaan. Di era posmodern, akal budi dan hati nurani cenderung diabaikan, meskipun di era Renaisans manusia kembali pada rasionalitasnya (akal budi), namun yang terjadi justru memunculkan kekecewaan karena timbulnya berbagai macam krisis yang diakibatkan oleh penggunaan teknologi manusia (sebagai hasil akal budi) yang mengeksploitasi alam tanpa batas. 


\section{Akal Budi Manusia}

Salah satu sebab terjadinya krisis kemanusiaan sebagaimana yang dibahas di atas adalah karena krisis nalar atau akal, karena nalar tidak lagi didasari pada fitrawi dan kemanusiaan. Padahal perbedaan utama antara manusia dengan binatang adalah terletak pada kepemilikan akal dan hati nurani. "Al-Insanu hua hayawanu natiqun" begitu silogisme terkenal dari Aristoteles. Manusia tak ubahnya adalah salah satu jenis mamalia, ia digambarkan sebagai binatang yang rasional serta memiliki pengetahuan dan agama (Muthahhari 2013: 7).

Manusia menurut al-Qur'an adalah sebagai masterpiece, ahsani al-taqwim (sebaik-baik ciptaan), namun di sisi lain manusia adalah asfala safilin (serendahrendahnya), (QS. Al-Tiin (95): 1-8). Tergantung bagaimana manusia menggunakan akal budinya dan melestarikan kebudayaannya, menjadi asfala al-safilin (serendah-rendahnya) apabila manusia tidak lagi menggunakan akal budinya dan hati nuraninya, untuk bersikap bijaksana dan berbuat kebajikan. Apabila ia menggunakan akal budinya dan hati nuraninya secara tepat, bersikap bijaksana dan berbuat kebajikan, ia menjadi ahsani altaqwim (sebaik-baik ciptaan).

Modal utama manusia untuk menjadi baik dan bijaksana adalah melalui akal budi dan hati nuraninya. Sejarah manusia sejak Nabi Adam as., hingga Nabi
Muhammad saw. lebih lama hidup tanpa Kitab Suci daripada dengan Kitab Suci. Kitab Suci Zabur, Taurat, Injil dan alQur'an diturun dari zaman Nabi hingga Nabi Muhammad saw., jauh sebelum itu hingga Nabi Adam, manusia hidup tanpa Kitab Suci, hal ini dapat ditafsirkan bahwa bekal utama manusia untuk bersikap bijaksana berbuat baik, adalah dari akal budi dan hati nurani manusia.

Kitab Suci al-Qur'an bukanlah subjek aktif atas proses berlangsungnya kehidupan manusia. Al-Qur'an bukan pelaku perubahan, pembangunan, sejarah dan peradaban umat manusia. Al-Qur'an itu adalah alat perubahan, dan secara sederhana dapat dikatakan bahwa al-Qur'an akan sia-sia bagi manusia yang tidak menggunakan modal utamanya sebagai manusia, yakni aktivitas akal (Nadjib 2009: 248). Sebagaimana tampak dalam alQur'an yang berkali-kali difirmankan "Apakah engkau tidak berfikir?", "Apakah engkau tidak menggunakan akal?" (Nadjib 2009: 249). Jadi akal dan agama bukanlah sesuatu bertentangan, bahkan agama akan berguna bagi orang yang berakal, maka apabila agama menolak akal/nalar, akan menjadi agama yang menolak eksistensi dirinya sendiri. Karena agama tanpa nalar menjadi sia-sia. Sebagaimana agama tanpa budaya lokal menjadi kosong.

Oleh karena itu prinsip utama menjalani Islam adalah, jihad, ijtihad, dan mujahadah. Kalau jihad adalah segala 
upaya perjuangan manusia menghidupi kehidupan. Ijtihad adalah perjuangan intelektual. Sedangakan mujahadah adalah perjuangan spiritual. Masyarakat Barat dan Jepang Korea China sangat aktif melakukan ijtihad dan menguasai peradaban. Kaum Muslimin terlalu aktif bermujahadah tanpa imbangan ijtihad sehingga produknya adalah dekadensi dan inferioritas (Nadjib 2009: 249. Bahkan sekarang ini orang Islam justru sibuk dengan jihad melawan sesama orang Islam sendiri yang dianggap kafir, sesat dan harus segera diusir.

Menurut hemat penulis, dengan menggunakan akal budinya, yakni dengan prinsip-prinsip epistemologi dan dasardasar logika yang tepat, manusia mampu memperoleh pengetahuan yang benar serta mampu melahirkan kearifan-kearifan lokal yang luhur. Kearifan lokal sendiri merupakan hasil dari perenungan panjang manusia yang sudah terbukti kematangannya dalam menyelesaikan dinamika sejarah peradaban manusia.

Dengan akal budinya, manusia menjadi tidak mudah terjebak dalam keraguankeraguan yang menimbulkan tekanan psikologis, yang membuat seseorang secara serampangan mencari sandaran dan cenderung meninggalkan kritisisme dan terjebak dalam dogmatisme agama. Oleh karena itu, akal sehat mendahului agama, agama akan sia-sia bagi seseorang yang tidak menggunakan akalnya. Dengan kembali ke akal budinya manusia akan kembali menemukan kebudayaannya, manusia akan kembali kepada akar kemanusiaanya.

\section{Hati Nurani Manusia}

Intrumen yang kedua setelah akal adalah hati, dalam epistemologi, akal disebut ilmu hushuli sedangkan hati sering dikaitkan dengan ilmu hudhuri. Dengan akal akan memunculkan karya, dengan hati akan memunculkan karsa, menciptakan rasa keindahan.

Hati dalam khasanah Islam klasik juga disebut sebagai tradisi keilmuan 'irfani, yang dalam istilah al-Jabiri (1990) dibedakan dengan tradisi keilmuan bayani, yaitu tradisi keilmuan yang bersumber dari 'teks' (wahyu), sedangkan dalam tradisi keilmuan 'irfani sumbernya adalah experience (pengalaman). Menurut Amin Abdullah exsperience ini mencakup semua pengalaman otentik baik itu hal-hal yang sifatnya rohani (spiritual) atau hal-hal dalam keseharian, perasaan rasa sakit, sedih, senang dan sebagainya, dapat dirasakan secara langsung oleh seluruh umat manusia apapun warna kulit, ras, budaya dan agama yang dipeluknya, tanpa harus mengatakannya terlebih dahulu lewat pengungkapan bahasa maupun logika (Abdullah 2012: 209).

Pengalaman hidup sehari-hari yang otentik, sesungguhnya merupakan pelajaran yang tidak ternilai harganya. Ketika 
manusia menyaksikan alam semesta yang mengagumkan, dalam lubuk hatinya yang terdalam telah mengetahui adanya Dzat yang Maha Suci dan Maha segalanya. Untuk mengetahui Dzat yang Maha Pengasih dan Penyayang, orang tidak perlu menunggu teks, pengalaman konkret pahitnya konflik, kekerasan dan disintegrasi sosial, sebagai akibat yang ditimbulkannya bisa dirasakan oleh siapa pun, tanpa harus dipersyaratkan mengetahui teks-teks keagamaan yang biasa dibacanya (Abdullah 2012: 208).

Dalam kehidupan selalu ada dunia yang dihayati dan yang dikatakan atau dipersepsikan. Dunia yang dihayati atau renungi ini adalah berupa pengalaman kebudayaan. Dalam penghayatan hidup, ada istilah mengalami 'asam-manisnya kehidupan' itu berkaitan dengan pengalaman kebudayaan. Untuk itulah prinsip memahami keberadaan orang, kelompok dan penganut agama lain (Verstehen; Understanding Others) dengan cara menumbuhsuburkan sikap empati, simpati, social skill serta berpegang teguh pada prinsip-prinsip universal reciprocity (jika merasa sakit dicubit, maka janganlah mencubit orang lain) akan mengantarkan tradisi keilmuan 'irfani pada pola pikir yang lebih bersifat unity in difference, tolerant dan pluralist (Abdullah 2012: 210)

Menurut hemat penulis, jika menyaksikan konflik yang terjadi, melihat tingkat penyebabnya yang adalah berupa hal-hal yang kecil seperti hanya berbeda pandangan intern agama, hal tersebut menunjukkan bahwa untuk sekedar menahan diri dan memilih damai, hati nurani manusia cenderung diabaikan, bahkan untuk hanya bersikap tidak tega.

\section{Kesimpulan}

Salah satu fungsi agama adalah untuk menjaga manusia dan kebudayaaanya (kemanusiaannya). Namun sayangnya kebudayaan tidak lagi tampak dan bahkan dibid'ahkan atas nama agama, dan yang sering terjadi adalah konflik-konflik agama, yang penyebabnya ternyata adalah pertama; gagalnya kemanusiaan yang diakibatkan oleh krisis modernisme, di mana teks suci tidak lagi dipahami secara komprehensif. Ketika nalar ditinggalkan dan nurani kemanusiaan tidak lagi menjadi panduan serta kearifan lokal dilupakan. Akibatnya kekerasan menjadi pilihan.

Penyebab kedua adalah adanya kesempitan berfikir dan krisis kebudayaan lokal, manusia mudah sekali terjebak pada krisis eksistensial, adanya kegagalan intelektual, kebudayaan lokal tak lagi memberikan ketenangan jiwa, manusia menjadi mudah marah dan anarkis. Hal ini seharusnya membuat kita tersadar bahwa musuh kita sesungguhnya bukanlah siapasiapa, namun musuh kita sekarang ini adalah kesempitan berpikir. Peran agama 
yang sesungguhnya adalah mengubah cara pandang manusia terhadap realitas. Apabila sebelumnya realitas hanyalah materi, agama memberikan ruh atau spirit padanya. Apabila sebelumnya sebuah tradisi itu sepi dari nuansa 'ilahiyah, maka Islam memberikan makna Tauhid kepadanya. Agama seharusnya mampu memberi pemahaman yang mendalam tentang pentingnya mencari makna dalam setiap realitas sehingga manusia tidak mudah goyah dan tergerus oleh arus zaman.

Oleh karena itu, lebih baik mundur dua langkah dahulu, tidak melulu membicarakan agama dengan ngotot. Belajar bersikap rendah hati. Bahwa menggunakan akal budi dan hati nurani secara benar, serta mengapresiasi kearifankearifan lokal leluhur, mampu membentengi manusia dari konflik.

Menjadi manusia hati yang baik secara budaya terlebih dahulu, mempunyai rasa belas-kasih, mempunyai sikap toleransi dan mampu menggunakan rasa kemanusiaan, sebelum manusia memperdebatkan tentang ilmu-ilmu agama. Karena tanpa rasa kemanusiaan, membuat manusia cenderung tidak mempunyai sikap toleransi, mudah marah, mengkafirkan, mengusir dan melakukan anarkisme kepada pihak yang berbeda pemahaman agamanya. Maka untuk terwujudnya masyarakat yang damai menurut penulis adalah lebih mengandalkan kemanusiaan terlebih dahulu yaitu kembali pada tradisi dan kebudayaannya. Budaya mengajarkan manusia cinta kasih dan menerima orang lain dengan sikap rendah.[]

\section{Daftar Pustaka}

Abdullah, M. Amin. 2012. Islamic Studies di Perguruan Tinggi, Pendekatan Integratif-Interkonektif. Yogyakarta: Pustaka Pelajar.

—_- 2009. "Mempertautkan Ulum AlDiin, Al-Fikr Al-Islamiy dan Dirasat Islamiyyah: Sumbangan Keilmuan Islam untuk Peradaban Global" dalam Marwan Saridjo (ed), Mereka Bicara Pendidikan Islam; Sebuah Bunga Rampai, Jakarta: DPP GUPPI.

Azra, Azzumardi. 2000. Renaisans Islam Asia Tenggara (Sejarah Wacana \& Kekuasaan). Bandung: Rosda Karya.

Bagir, Haidar. 2001. "Kembali Berfilsafat, Kembali Menjadi Manusia". sebuah pengantar, dalam Oliver Leaman, Pengantar Filsafat Islam, Sebuah Pendekatan Tematis, Bandung: Mizan.

Bakar, Osman Bin. 2003. "Tasawuf di Dunia Melayu-Indonesia", dalam Seyyed Hossein Nasr, ed. Ensiklopedi Tematis Spiritualitas Islam, Manifestasi. Bandung; Mizan.

Efendy, Ahmad Fuad. 2012. Sejarah Peradaban Arab \& Islam. Malang: Misykat Indonesia.

Gellner, Ernest. 1992. Postmodernism Reason and Religion. London: Routlege. 
Hamidy, U. U. 2014. Jagad Melayu dalam Lintasan Budaya di Riau, Pekanbaru: Bilik Kreatif Press.

Hardiman, F. Budi. 2012. Humanisme dan Sesudahnya. Jakarta: KPG.

Al-Jabiri, Muhammad Abid. 1990. Bunyah alAql al-Araby. Beirut: Markaz Dirarat alWahidah al- Arabiyah.

Muthahhari, Murtadha. 2013. Falsafah Agama dan Kemanusiaan, Perspektif al-Qur'an dan Rasionalisme Islam, Yogyakarta: Rausyan Fikr.

Nadjib, Emha Ainun. 2009. "Masterpiece Karya Allah: Menemukan Kembali al-
Qur'an", dalam Demokrasi La Roiba Fih, Jakarta: Kompas.

-_ $2014 . \quad$ "Banawa-Sekar." (https://www.caknun.com/2014/ban awa-sekar/). diakses pada tanggal 05 Maret 2017.

Naisbitt, John dan Patricia Aburdene. 1990, Megatrend 2000, Sepuluh Arah Baru untuk Tahun 1990-an. Jakarta: Binarupa Aksara.

Yazdi, Mehdi Ha'iri, 1994, Ilmu Hudhuri, Prinsip-prinsip Epistemologi dalam Filsafat Islam Dari Suhrawardi via Wittgenstein, Bandung: Mizan. 


\section{Author Guidelines}

\section{A. Persyaratan Umum}

1. Naskah merupakan hasil penelitian sosial keagamaan dan modernitas yang sudah diformat sesuai pola penulisan artikel jurnal ilmiah.

2. Naskah diutamakan ditulis dalam Bahasa Inggris.

3. Naskah merupakan karya orisinil (bukan plagiasi) dan belum pernah dimuat di jurnal atau media cetak/online lainnya.

4. Naskah dikirim ke Redaksi JSW: Jurnal Sosiologi Walisongo melalui submission Open Journal Systems (OJS) pada http://journal.walisongo.ac.id/index.php/jsw

5. Naskah diketik menggunakan Microsoft Word format RTF, font Times New Roman, size 12 pt, 1,5 spasi, ukuran halaman A4, dengan panjang tulisan 20-25 halaman (sekitar 5.000 - 7.000 kata).

6. Untuk menperoleh keterangan lebih lanjut, silakan menghubungi redaksi melalui email: jurnal.sosiologi@walisongo.ac.idatau menghubungi kantor redaksi (024) 76435986.

\section{B. Persyaratan Khusus}

1. Naskah merupakan hasil penelitian dalam bidang sosial keagamaan dan modernitas.

2. Naskah tidak mencantumkan nama penulis, instansi, dan alamat email. Nama penulis, instansi, dan alamat email dicantumkan saat melakukan registrasi OJS dan pengisian metadata naskah.

3. Naskah memuat:

a. Judul, dengan ketentuan:

- Judul merupakan rumusan pokok bahasan yang singkat, padat, dan jelas.

- Dalam judul sudah tercantum variabel-variabel utama penelitian.

- Judul diketik dengan hurup kapital tebal (capital, bold).

b. Abstrak, dengan ketentuan:

- Abstrak ditulis dalam bahasa Inggris dan bahasa Indonesia. 
- Abstrak merupakan intisari dari pokok bahasan naskah.

- Abstrak ditulis dalam satu paragraf berjarak satu spasi, dengan panjang 100250 kata.

- Abstrak disajikan secara singkat dan jelas, dengan memuat empa. argumentasi logis, perlunya dilakukan penelitian untuk memecahkan masalah, pendekatan yang digunakan (metode), hasil yang dicapai, serta simpulan yang diperoleh (IMRAD: introduction, methods, results, analysis and discussions).

c. Kata Kunci (keywords) maksimal 5 (lima) kata.

d. Isi naskah, dengan sistematika sebagai berikut:

- Pendahuluan yang meliputi latar belakang masalah, perumusan masalah, tujuan dan manfaat penelitian, serta metodologi yang digunakan (IMRAD: introduction, methods, results, analysis and discussions).

- Review pustaka yang berisi kajian teoretik dan hasil penelitian terdahulu yang relevan.

- Hasil dan pembahasan.

- Simpulan dan rekomendasi.

- Daftar pustaka.

4. Rujukan menggunakan ASA (American Sociological Association).[] 


\section{ACKNOWLEDGEMENTS}

The members of the editorial team of JSW: Jurnal Sosiologi Walisongo extend the gratitude to all the reviewers who have contributed to the peer review process of the manuscripts in Vol 1, No 2 (2017). Professional support and assistance from all respected reviewers have made this journal qualified to be published:

1. Abu Rokhmad, Universitas Islam Negeri Walisongo, Semarang

2. Agus Nurhadi, Universitas Islam Negeri Walisongo, Semarang

3. Misbah Zulfa Elizabeth, Universitas Islam Negeri Walisongo, Semarang

4. Muhyar Fananai, Universitas Islam Negeri Walisongo, Semarang

5. Najahan Musyafak, Universitas Islam Negeri Walisongo, Semarang

6. Thohir Yuli Kusmanto, Universitas Islam Negeri Walisongo, Semarang

7. TriMarhaeni Pudji Astuti, Universitas Negeri Semarang 


\section{\begin{tabular}{l|l} 
JW & $\begin{array}{l}\text { JURNAL } \\
\text { SOSIOLOGI } \\
\text { WALISONGO }\end{array}$
\end{tabular}}

JSW: Jurnal Sosiologi Walisongo - ISSN 2503-3166 (print) ISSN 2503-3182 (online) is a critical, reflective, and transformative academic media that is published by Laboratorium Sosiologi, Fakultas IImu Sosial dan IImu Politik, Universitas Islam Negeri Walisongo Semarang, in the effort for developing the discipline of Sociology having the perspective of unity of sciences. Article is based on research in all division of sociology like sociology of religion, sociology of politic, sociology of law, sociology of development, urban/rural sociology, democracy, social ethic, anthropology, community development, social philosophy, gender, and social welfare. 